\title{
Evaluating future scenarios for the power generation sector using a Multi-Criteria Decision Analysis (MCDA) tool: The Portuguese case
}

\author{
Fernando Ribeiro, Paula Ferreira*, Madalena Araújo \\ University of Minho, Center for Industrial and Technology Management, Campus Azurem, 4800-058 Guimaraes, Portugal
}

\section{A R T I C L E I N F O}

\section{Article history:}

Received 22 June 2012

Received in revised form

21 December 2012

Accepted 27 December 2012

Available online 14 February 2013

\section{Keywords:}

Multi-criteria decision tools

Energy scenarios

Power supply

\begin{abstract}
A B S T R A C T
A Multi-Criteria Decision Analysis (MCDA) tool was designed and used to support the evaluation of different electricity production scenarios. The MCDA tool is implemented in a user-friendly Excel worksheet and uses information obtained from a mixed integer optimization model, to produce a set of optimal schemes under different assumptions. Given the input, the MCDA allowed ranking different scenarios relying on their performance on 13 criteria covering economic, job market, quality of life of local populations, technical and environmental issues. The MCDA tool was used by a group of experts and academics with background in economics, engineering and environment. Regarding the totality of results, both the most and least expensive scenarios ranked first the same amount of times. These scenarios were, respectively, "Coal", relying mainly in new coal power plants and "Maximum Renewable", relying mainly in new wind and hydro power facilities. The opinions were divided towards these two solutions with different fundamental characteristics: "Maximum Renewable" with costs higher than "Coal" but leading to substantial reduction of the external energy dependency. Sensitivity analysis suggests that, although the costs are regarded as the most important criterion, those who had different rankings in their preferences have different attitudes towards other criteria.
\end{abstract}

(c) 2013 Elsevier Ltd. All rights reserved.

\section{Introduction}

\subsection{Background and motivation}

Over the last two decades, international treaties, such as Kyoto Protocol, have been signed, and strategies to mitigate $\mathrm{CO}_{2}$ emissions have arisen in all the developed world nations. At the same time, Sustainable Development is becoming part of political discourse in the European Union. According to the European Union Sustainable Development Strategy (EUSDS), Sustainable Development envisages the "continuous improvement of the quality of life of citizens through sustainable communities that manage and use resources efficiently and tap the ecological and social innovation potential of the economy, so as to ensure prosperity, environmental protection and social cohesion" [1].

As a result, the electricity production planning gets more constrained than before, resulting in a multi-objective problem [2]. What was regarded in the past as a cost minimization problem

\footnotetext{
* Corresponding author. Tel.: +351 253511670; fax: +351 253510343.

E-mail address: paulaf@dps.uminho.pt (P. Ferreira).
}

should now be evaluated also under a Sustainable Development perspective. In previous works, we identified papers concerning sustainability criteria in power systems planning [3,4], and concluded that the methodologies explicitly expressing economic, social and environmental criteria fall mostly under the umbrella of Multi-Criteria Decision Analysis (MCDA).

When using multi-criteria decision methodologies, one has to have in mind that there are no universal best solutions, as results are made upon personal judgement of different criteria. Therefore, for the present work, we invited a panel of experts on energy systems to map the diversity of opinions and preferences for the future of the Portuguese electricity system. We designed a new MCDA tool for the evaluation of different electricity generation scenarios and presented it to a group of experts in power systems. The use of the MCDA tool was then demonstrated for the evaluation of possible electricity scenarios drawn for Portugal in 2020, according to the experts input. Portugal depends strongly on a mix of natural gas, coal, wind and hydro power. Given that high potential for developing renewables still exists, there is higher uncertainty about what will become the power system within ten years. This uncertainty is higher than in other countries where lower potential exists for developing renewables, and choices are more limited. 
Therefore it was decided to test the MCDA using Portugal as an example, although our work can easily be adapted to other countries. Present work can give valuable inputs to energy decision makers for similar systems. The main objective of the paper is to assess the experts' opinion on the proposed scenarios and considered criteria, demonstrating then the importance of experts' participation in structured energy planning decisions.

The criteria used in the evaluation cover Sustainable Development (social, cost and environmental) issues, among others, visual impacts and technical issues of power systems, as addressed in Section 3. We retrieved the criteria from both interviews conducted in a previous phase of the work [5] and from the literature.

\subsection{Energy decision-making and Multi-Criteria Decision Analysis (MCDA)}

Literally hundreds of MCDA methodologies have been proposed [2]. These have been applied to a wide array of examples in the energy sector [6]. Recent examples range from assessment of applications in bioenergy systems [7] to space heating technologies ranking [8], or sustainability assessment of domestic hot water technologies [9], among many others. To what concerns the purpose of the present work, more specifically electricity and power systems, MCDA has also been applied. Following Hobbs and Meier [10] definition of electricity power planning, "the selection of power generation and energy efficiency resources to meet customer demands for electricity over a multi-decade time horizon", a number of papers found in the literature serve as a contribution to this topic, more specifically in evaluation of projects, technologies and scenarios. Some papers surveyed from the literature will serve as examples in the remainder of this section.

Discrete MCDA models, do not involve a description of the objectives or constraints in mathematical functions, but rather a characterization of a finite set of alternatives or projects aimed to be compared and evaluated. A large number of these studies perform comparisons between different electricity power production options, technologies or projects. Kahraman [11] used fuzzy Analytic Hierarchy Process (AHP) to compare renewable energy technologies. The fuzzy set theory was found useful for treating vague information and uncertainty. Their study concluded that wind power was the most attractive technology under the set of criteria they evaluated. Kaya [12] conducted an integrated MCDA approach, combining methodologies AHP and VIKOR (VIsekriterijumsko KOmpromisno Rangiranje), to aid the selection of the best technology in the first place, and evaluate the best location for wind power in the second place: this paper serves as an example where both technologies and projects were evaluated. Still in the application to specific projects, Choudhary [13] used a fuzzy AHP-TOPSIS (Technique for the Order of Prioritization by Similarity to Ideal Solution) approach for aiding the location for implementation of a thermal power plant.

Energy planning based on discrete models relies frequently on the comparative assessment of alternative scenarios explicitly known a priori. Each scenario describes a possible expansion plan and gives information about its technical, economic, environmental and social characteristics. The advantage of using scenarios is that they do not evaluate technologies per se as the cases we've presented so far in this section, but rather evaluate whole solutions that satisfy the electricity demand: more concretely, wind power can be the most "sustainable" technology on its own, but cannot satisfy the entire demand of a country on its own due to its variable production nature, so it will be used coupled with other technologies. The resulting feasible mix constitutes a scenario. MCDA applications are proven to be useful and have been extensively used to evaluate these scenarios.

Using MCDA allows the evaluation of the interaction between different technologies, by using this information in reliability indexes, such as the case of Prete [14]. Their scenarios are also evaluated under technical criteria, such as economic, environmental and social indexes. One example of an integrated approach to decision-making in energy systems considering sustainability criteria is McCollum [15], where an "optimal" scenario is created after criteria are weighted. Other works incorporate valuable technological aspects of power systems, such as Heinrich et al. [16], which provided a methodology to evaluate scenarios for generation capacity expansion under uncertainty in South Africa, allowing also

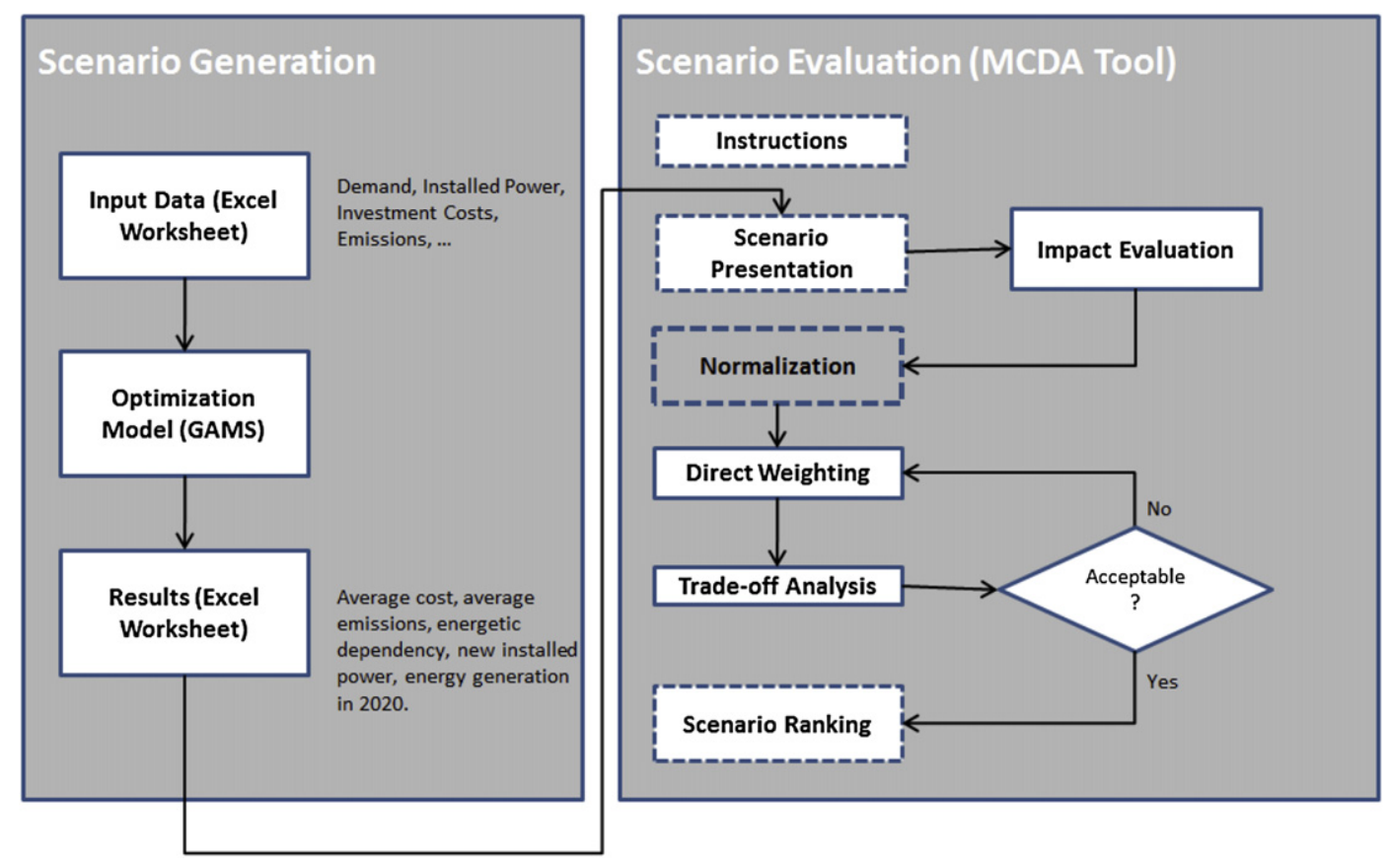

Fig. 1. Methodological approach of the research. 

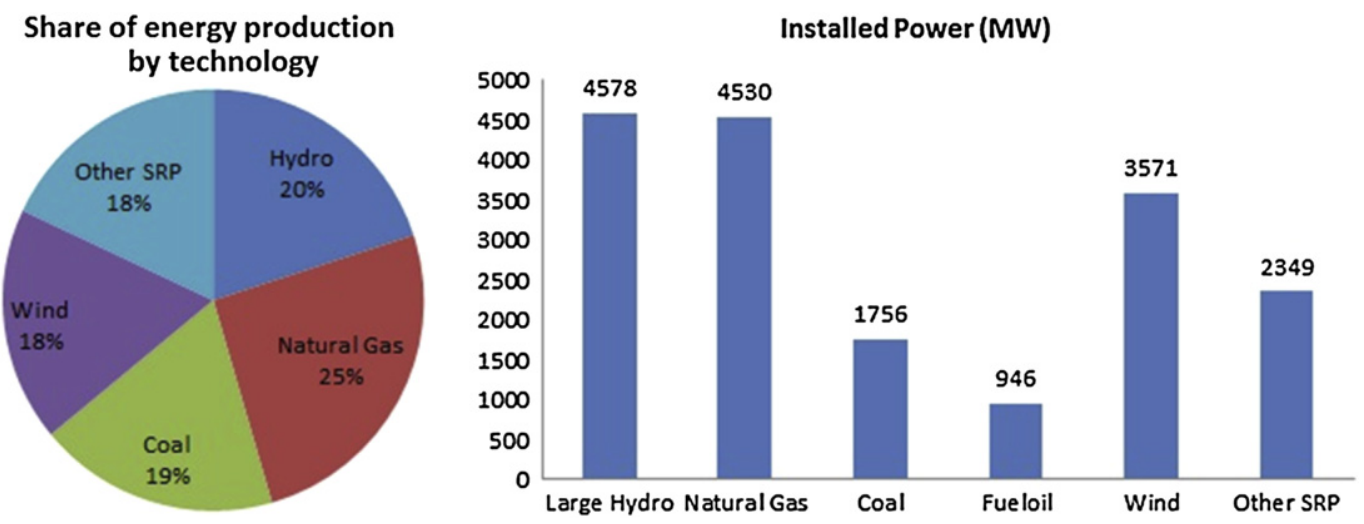

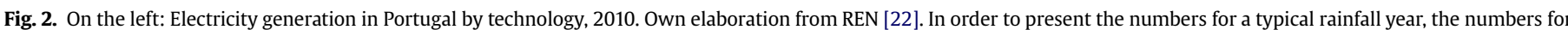

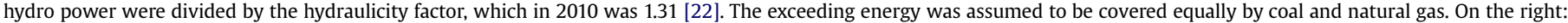

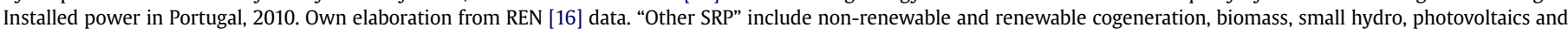
wave power.

for sensibility analysis. Talinli [17] focused on the choice of energy production processes scenarios resourcing to fuzzy-AHP, in collaboration with academics, engineers and an economist using Turkey as case-study. More recently, Trutnevyte [18] applied a participatory methodology to both create scenarios and evaluate them with MCDA for a Swiss community, in collaboration with academics, energy consumers, energy suppliers and retailers. Other examples among many others include [19] who used PROMETHEE (Preference Ranking Organization Method for Enrichment Evaluation) to evaluate scenarios of renewable energy integration in the Austrian energy system [20], who applied an MCDA method in which eight participants used direct weighting to evaluate five energy scenarios in North West of England or [21] who identified five possible scenarios for Belgrade energy system, and evaluated them using MCDA to obtain a sustainability index.

For the present work, and following Hobbs and Meier [10] recommendations, scenario evaluation seemed to be the appropriate approach, given the possibility to evaluate sustainability questions along with others such as the system reliability and equilibrium of the mix, impossible to evaluate if technologies were being compared outside the context of the existing power system.

The remainder of the paper is as follows: Section 2 describes the methodological approach of the paper and Section 3 presents and discusses results of the proposed methodology implementation for the Portuguese case. Finally, Section 4 highlights conclusions and identifies directions for future work.

\section{Methodology}

As stated above, this paper aims at performing multi-criteria evaluation of electricity production scenarios for Portugal. In this section the creation of scenarios is explained, along the evaluation phase. Fig. 1 summarizes the methodological approach to the problem. The two main blocks of the methodology are Scenario Generation and Scenario Evaluation (MCDA Tool). Sections 2.1 and 2.2 are dedicated to each one of these topics.

\subsection{Scenario generation}

Electricity scenarios represent situations that may occur in the future but are strongly influenced by the currently existing power system. The case under research refers to the Portuguese electricity system, so before presenting the scenarios proposed for the evaluation with the MCDA, the present situation of the Portuguese electricity system is briefly introduced.
Electricity in Portugal is mainly generated from thermal, large hydro and wind power, as described in Fig. 2. Thermal power is mostly provided by coal and CCGT (combined cycle gas turbines) power plants. Special Regime Production (SRP) includes all the technologies benefiting from a non-dispatch special regime including renewable energy sources (RES) and cogeneration. In Fig. 2 the SRP is divided in Wind Power and "Other SRP".

Given the high share provided with hydro power, the rainfall characteristics have a great influence upon the electricity system. As a result, the hydro electricity production suffered strong variations from 2006 to 2010, although no significant modifications were made in terms of installed power. ${ }^{1}$

In 2007, the Portuguese state launched a new plan for installing more hydro power, known as PNBEPH (Plano Nacional de Barragens de Elevado Potencial Hidroeléctrico) [23]. It forecasted an increase in installed hydro power by $2059 \mathrm{MW}$ until the year 2020, aiming to reduce the unused national hydro power potential from 54\% to $33 \%$. This was expected to be achieved by two means: reinforcing the installed power of already existing facilities (909 MW), and building ten new hydro power plants totalling $1150 \mathrm{MW}$ of installed power. Among these projects, some include pumping capacity. The use of pumping was justified by the need to complement additional wind power to be installed: given that wind farms produce more in off-peak hours when electricity prices are lower, this energy can be used to pump water back to dams, so that hydro power can be generated during the hours of higher consumption and higher electricity prices. In 2007 the PNBEPH forecasted that in 2010 Portugal would reach $5100 \mathrm{MW}$ of installed wind power, but this value contrasted with the 3751 MW achieved in reality [24]. The future of the Portuguese power system remains uncertain, and in the remainder of this section, we explore some possible scenarios for 2020 .

To create the scenarios we resourced to a Mixed Integer Linear Programming (MILP) model, programmed in GAMS (General Algebraic Modelling System), as described in Pereira et al. [25]. The model does not attempt to simulate the power grid in real-time, but rather a higher-level planning approach. Two objective functions exist, both costs and emissions minimization of the electricity system. The program calculates the minimization for a 10 year period with a monthly time step. There exists an equilibrium constraint, to guarantee that in every month of every year the

\footnotetext{
1 The yearly variation of hydro power production is reflected in the so-called "hydraulicity factor", which equals 1 for an average year.
} 
Table 1

Characterization of the scenarios generated by the MILP.

\begin{tabular}{|c|c|c|c|c|c|c|}
\hline \multirow[t]{2}{*}{ Scenario } & \multicolumn{2}{|l|}{ Constraints } & \multicolumn{4}{|l|}{ Results } \\
\hline & $\begin{array}{l}\text { Minimum } \\
\text { renewable } \\
\text { quota }\end{array}$ & $\begin{array}{l}\text { New } \\
\text { installed } \\
\text { technologies }\end{array}$ & $\begin{array}{l}\text { New } \\
\text { installed } \\
\text { power }\end{array}$ & $\begin{array}{l}\text { Cost } \\
(€ / \mathrm{MWh})\end{array}$ & $\begin{array}{l}\text { Emissions } \\
\left(\mathrm{CO}_{2} \text { ton/GWh }\right)\end{array}$ & $\begin{array}{l}\text { External } \\
\text { energy } \\
\text { dependency }\end{array}$ \\
\hline Base & $45 \%$ & All technologies allowed & $\begin{array}{l}700 \mathrm{MW} \text { coal, } 1000 \mathrm{MW} \text { hydro, } \\
4400 \mathrm{MW} \text { wind, } 1180 \mathrm{MW} \text { other SRP }\end{array}$ & 25.69 & 262 & $32 \%$ \\
\hline Natural gas & Not included & Only CCGT allowed & $2350 \mathrm{MW}$ natural gas, $1180 \mathrm{MW}$ other SRP & 25.24 & 294 & $53 \%$ \\
\hline Coal & Not included & All technologies allowed & 2550 MW coal, 1180 MW other SRP & 23.75 & 360 & $55 \%$ \\
\hline Hydro-gas & $45 \%$ & $\begin{array}{l}\text { Only CCGT and hydro } \\
\text { power allowed }\end{array}$ & $\begin{array}{l}2050 \text { MW natural gas, } 2000 \text { MW hydro, } \\
1180 \text { MW other SRP }\end{array}$ & 25.96 & 296 & $45 \%$ \\
\hline $\begin{array}{l}\text { Maximum } \\
\text { renewable }\end{array}$ & $70 \%$ & $\begin{array}{l}\text { Only hydro and wind } \\
\text { power allowed }\end{array}$ & $\begin{array}{l}2000 \text { MW hydro, } 4400 \mathrm{MW} \text { wind, } \\
1180 \text { MW other SRP }\end{array}$ & 26.37 & 250 & $28 \%$ \\
\hline
\end{tabular}

demand is guaranteed by production. Other constraints exist, so it is possible to guarantee a minimum renewable energy quota per year, and also to guarantee a given level of $\mathrm{CO}_{2}$ emissions. Hydro power plays an important role, so the storage capacity is taken into account, which implies minimum and maximum reservoir levels and pumping capacity. The reserve margin of the system is also taken into account, allowing to model potential reductions due to lack of wind power and hydro power production [25].

We used the source code to create scenarios with different characteristics. These scenarios represent different possible futures for the Portuguese power generation system in a 10 year range, departing from the present characteristics of the system. Each scenario is characterized by a set of newly installed power plants of each technology that, together with the already existing ones, will meet the electricity demand. The technologies considered as variables of the optimization model were hydro power, wind, natural gas and coal; on the other hand non-wind Special Regime Production was assumed to remain as a predefined parameter for every scenario. Nuclear energy has been debated for many decades in Portugal, but presently there is no forecast that any power plant of this type will be built. Given the long planning time that it takes to build the power plant, it is unlikely that it will happen within 10 years.

The assumed demand and peak load were computed according to the forecasts available in the Portuguese National Renewable Energy Action Plan [26]. According to this data, demand, which was about 52 TWh in 2010, is expected to increase 12 TWh in 10 years. The rate of the peak load growth was adjusted accordingly to the rate of consumption growth. The present values of non-Wind SRP installed power, the generated electricity from these sources, as well as their expected growth for the planning period, were computed and included in the input worksheet. This information was elaborated from information collected in the report available in the Portuguese Renewable Action Plan ([26], p. 94 and 95). For calculating the non-wind SRP costs [27], values were assumed.

In Table 1, five possible scenarios of electricity generation in the year 2020 are presented. Note that they differ on the newly installed power plants but depart from the same situation of installed power in 2010, presented in Fig. 2. The scenarios consist in: a first moderated scenario following a business-as-usual approach, a second scenario mainly relying on investment in new natural gas power plants, a third scenario mainly relying on investment in new coal power plants, a fourth scenario relying on investment in a mix of new hydro and gas power plants and a fifth scenario relying on investment in a mix of new hydro and wind power plants. Obviously, none of these scenarios can be considered highly likely to happen in this exact form due to the infinity of possible and distinct combinations. However, given the present state of the Portuguese electricity system, these are five possible strategies representative of different energy policy trends. The evaluation of more scenarios demands additional input information and higher response time on the MCDA tool. In order to ensure the effective participation of experts it was decided to keep the number of scenarios limited to the above described ones.

Since the objective function of the model is the minimization of the total costs, different constraints were used to diversify the scenarios. These constraints were of two types: allowing the program to use or not power plants of a specific technology, and, on the other hand, imposing or not a renewable energy quota to be met in 2020. Not using these constraints would result in the model adding only new coal power plants to cover the growing demand, the least costly solution according to the predefined data.

The results demonstrate the main differences between scenarios when cost, $\mathrm{CO}_{2}$ emissions (representing the average specific cost and average emission factor for the 10 year range) and external energy dependency criteria in 2020 are considered. In particular, for the extreme cases "Coal" and "Maximum Renewable", these divergences are evident. The "Coal" scenario is the least costly one, but also leads to the highest external energy dependency (that is, highest share of coal and natural gas) and presents the highest $\mathrm{CO}_{2}$ emissions. The other extreme case, presenting lowest external energy dependency and less $\mathrm{CO}_{2}$ emissions is the "Maximum Renewable" scenario, which costs are about 11\% higher than for the "Coal" scenario.

\subsection{Criteria selection}

The criteria to be evaluated in the multi-criteria analysis process and their descriptions are given as follows in Table 2.

Information of investment, operation \& maintenance of the whole group of power plants is included in a single cost criterion. Positive impacts in industry, job creation and dependency on foreign fossil fuels have been an international concern for sustainable energy decisions $[6,10]$ with implications at national level [26]. Diversification of the electricity mix is also seen as important for sustainability goals [28] contributing to the security of supply. Local income, visual and noise impacts, as well as land use and public health were identified as important issues for local populations' standards of living, by the authors [5]. It is sometimes argued that the intermittency of the renewables implies they are benefited in terms of levelized costs [29]: therefore, a criterion that accounts for the dispatchable rate of power on each solution was included. According to Ref. [30], the transmission system expansion requirements may be larger when renewable energy shares are higher; as the scenarios vary respecting to that aspect, the criterion was also proposed to be evaluated. Given the importance that $\mathrm{CO}_{2}$ emissions play in the economy nowadays, this criterion was also included. On a given criterion, $c$, every scenario, $s$, will most likely perform 
Table 2

Description of the criteria to be evaluated in the MCDA tool.

\begin{tabular}{|c|c|c|c|c|}
\hline$c_{i}$ & Name & Description & Reference(s) & Scenario score, $I_{s, c}$ \\
\hline$c_{1}$ & Costs & $\begin{array}{l}\text { Sum of fixed and variable costs, divided by the total } \\
\text { electricity produced during the planning period. The } \\
\text { fixed costs are related with the investment cost } \\
\text { applied to the new power plants and also with all } \\
\text { fixed O\&M costs. The variable costs include fuel and } \\
\text { variable O\&M costs for new and previously installed } \\
\text { power plants. }\end{array}$ & {$[25]$} & $\begin{array}{l}\text { Values in } € / M W h \text {, obtained } \\
\text { from the MILP model. User } \\
\text { cannot change values. }\end{array}$ \\
\hline$c_{2}$ & $\begin{array}{l}\text { National } \\
\text { industry }\end{array}$ & $\begin{array}{l}\text { Impact of the scenario on the dynamics of the } \\
\text { national industry. }\end{array}$ & {$[6,10,26]$} & $\begin{array}{l}\text { Score in ordinal scale, ranging } \\
\text { from } 1 \text { (worst) to } 5 \text { (best). Requires } \\
\text { user to attribute values according } \\
\text { to own perception. }\end{array}$ \\
\hline$c_{3}$ & $\begin{array}{l}\text { Energy } \\
\text { dependency }\end{array}$ & $\begin{array}{l}\text { Rate of dependency on foreign sources in year } 2020 \text {, } \\
\text { calculated as the sum of energy produced in thermal } \\
\text { power plants (coal, natural gas and non-renewable } \\
\text { cogeneration) divided by the total energy amount } \\
\text { produced. }\end{array}$ & {$[6,10,26]$} & $\begin{array}{l}\text { Values in \%, obtained from the } \\
\text { MILP model. User cannot change } \\
\text { values. }\end{array}$ \\
\hline$c_{4}$ & Employment & $\begin{array}{l}\text { Employment created by the construction, operation } \\
\text { and maintenance of the power plants. }\end{array}$ & {$[6,10,26,31]$} & $\begin{array}{l}\text { Values are number of jobs. Obtained } \\
\text { from the MILP model, based on Ref. [25]. } \\
\text { Although values are given, the user may } \\
\text { attribute different values according to } \\
\text { own perception. }\end{array}$ \\
\hline$c_{5}$ & Visual impact & $\begin{array}{l}\text { Impact caused by the construction of new power } \\
\text { plants upon the sightseeing. }\end{array}$ & {$[3-5]$} & $\begin{array}{l}\text { Score in ordinal scale, ranging from } 1 \\
\text { (worst) to } 5 \text { (best). Requires user to attribute } \\
\text { values according to own perception. }\end{array}$ \\
\hline$c_{6}$ & Noise & $\begin{array}{l}\text { Noise impact caused in neighbour areas by the new } \\
\text { infra-structures. }\end{array}$ & {$[3-5]$} & $\begin{array}{l}\text { Score in ordinal scale, ranging from } 1 \\
\text { (worst) to } 5 \text { (best), based on Ref. [26]. } \\
\text { Although values are given, user may attribute } \\
\text { values different according to own perception. }\end{array}$ \\
\hline$c_{7}$ & Local income & $\begin{array}{l}\text { Rents originated by land use, for both public and } \\
\text { private sectors. }\end{array}$ & {$[5]$} & $\begin{array}{l}\text { Score in ordinal scale, ranging from } 1 \text { (worst) } \\
\text { to } 5 \text { (best). Requires user to attribute values } \\
\text { according to own perception. }\end{array}$ \\
\hline$c_{8}$ & $\begin{array}{l}\text { Diversity } \\
\text { of mix }\end{array}$ & $\begin{array}{l}\text { Diversity of installed power, calculated according to } \\
\text { the Shannon-Wiener Index. }\end{array}$ & {$[28]$} & $\begin{array}{l}\text { Higher values are better. Obtained from the } \\
\text { MILP model, based on Ref. [33]. User cannot } \\
\text { change values. }\end{array}$ \\
\hline$c_{9}$ & $\begin{array}{l}\text { Rate of } \\
\text { dispatchable } \\
\text { power }\end{array}$ & $\begin{array}{l}\text { Ratio between the sum of installed power of coal, } \\
\text { CCGT, dam hydro power plants, and all the installed } \\
\text { power. }\end{array}$ & [29] & $\begin{array}{l}\text { Score is given in \%. Obtained from the MILP } \\
\text { model. User cannot change values. }\end{array}$ \\
\hline$c_{10}$ & $\begin{array}{l}\text { Investment in } \\
\text { Transmission } \\
\text { Network }\end{array}$ & $\begin{array}{l}\text { Additional investments required by the scenario. It } \\
\text { was assumed that wind power required the largest } \\
\text { investment in transmission network, followed by hydro } \\
\text { power. No additional investment was assumed to be } \\
\text { required by natural gas and coal power plants. }\end{array}$ & [30] & $\begin{array}{l}\text { Score in ordinal scale, ranging from } 1 \text { (worst) } \\
\text { to } 5 \text { (best). Although the values are given, the } \\
\text { user may attribute different values according to } \\
\text { own perception. }\end{array}$ \\
\hline$c_{11}$ & $\mathrm{CO}_{2}$ emissions & $\begin{array}{l}\text { Ratio between } \mathrm{CO}_{2} \text { emissions and the total electricity } \\
\text { generated in the overall planning period. }\end{array}$ & {$[25]$} & $\begin{array}{l}\text { Values are given in tons of } \mathrm{CO}_{2} \text { per GWh of } \\
\text { electricity produced in the planning period. } \\
\text { Obtained from the MILP model. User cannot } \\
\text { change values. }\end{array}$ \\
\hline$c_{12}$ & Land use & $\begin{array}{l}\text { Amount of land which becomes unusable by the } \\
\text { scenario. }\end{array}$ & [31] & $\begin{array}{l}\text { Values are given in } 1000 \mathrm{~km}^{2} \text {, based on Ref. [25]. } \\
\text { Obtained from the MILP model. Although values } \\
\text { are given, the user may attribute different values } \\
\text { according to own perception. }\end{array}$ \\
\hline$c_{13}$ & Public health & $\begin{array}{l}\text { Contamination of air, water, and general impact on } \\
\text { public health. }\end{array}$ & [32] & $\begin{array}{l}\text { Score is based on Ref. [26]. Obtained from the } \\
\text { MILP model. Although values are given, the user } \\
\text { may attribute different values according to own } \\
\text { perception. }\end{array}$ \\
\hline
\end{tabular}

differently. This performance is called "Scenario Score" and is represented by $I_{s, c}$. For example, costs are lower for the Coal scenario, so it is the scenario with the best performance in respect to this criterion. Other criteria are better when maximized, and that information is present in Table 2 . Since not all the impacts can be easily measured or agreed upon, it was decided that the user might play a role on valuing them, as detailed in Table 2, column Scenario Score.

\subsection{Methodology for the MCDA evaluation}

The proposed methodology in the present work falls in the category "value measurement methods" [2] and can be summarized as direct weighting with an additive value function for amalgamation. As a result, it involves three phases, already mentioned in Fig. 1: Impact Evaluation, Direct Weighting and Trade-off Analysis.
Impact Evaluation is the phase where a score ${ }_{s, c}$, is assigned to each scenario $s$ and criteria $c$. These values are then normalized, using a linear function, $v_{s, c}$, so that the best values become 1 and the worst values become 0 .

The user then assigns directly weights $w_{c}$ to each criteria $c$. Finally, for every criteria $c$, trade-offs are presented in terms of costs, while the user is still able to change weights according to his perceptions.

The final value for the scenario $s$ is calculated according to the Additive Value Function (AVF), as follows:

$\mathrm{AVF}_{S}=\sum w_{c_{i}} \times v_{S, c_{i}}$

where the higher the value, the better the solution is.

The weights should ideally "indicate how much the decision maker is willing to accept in trade-off between two criteria" [2]. A trade-off is a situation that involves a compromise, so that gaining 
Table 3

Trade-off assessment.

\begin{tabular}{|c|c|c|c|c|c|}
\hline & \multicolumn{5}{|c|}{ Scenario $s$} \\
\hline & Base & Natural gas & Coal & Hydro-gas & $\begin{array}{l}\text { Maximum } \\
\text { renewable }\end{array}$ \\
\hline score $_{s, \text { cost }}$ & 25.69 & 25.24 & 23.75 & 25.96 & 26.37 \\
\hline$v_{s, \text { cost }}$ & 0.26 & 0.43 & 1 & 0.15 & 0 \\
\hline score $_{s, \text { dependency }}$ & 0.3 & 0.53 & 0.55 & 0.47 & 0.28 \\
\hline$v_{s, \text { dependency }}$ & 0.93 & 0.07 & 0 & 0.3 & 1 \\
\hline $\begin{array}{l}\operatorname{Max}\left\{\text { score }_{\text {cost }}\right\} \\
\quad- \\
\quad \min \left\{\text { score }_{\text {cost }}\right\}\end{array}$ & 2.62 & 2.62 & 2.62 & 2.62 & 2.62 \\
\hline$w_{\text {cost }}$ & 100 & 100 & 100 & 100 & 100 \\
\hline$w_{\text {dependency }}$ & 50 & 50 & 50 & 50 & 50 \\
\hline$T_{S, c}$ & 1.22 & 0.09 & 0 & 0.39 & 1.31 \\
\hline$T_{s, c}(\%)$ & $5.1 \%$ & $0.4 \%$ & $0 \%$ & $1.6 \%$ & $5.5 \%$ \\
\hline
\end{tabular}

an amount of quality in one criterion implies decreasing quality in other criterion. In our case, we ask the MCDA user to perform tradeoff analysis of every criterion $c$ with cost. The user is asked how much would be worth to increase cost to quality in criterion $c$, from the worst situation to the better. Then trade-off is calculated using the following equation:

$T_{s, c}=\frac{w_{c}}{w_{\text {cost }}} \times v_{s, c} \times\left(\max \left\{\right.\right.$ score $\left._{\text {cost }}\right\}-\min \left\{\right.$ score $\left.\left._{\text {cost }}\right\}\right)$

Where:

$T_{s, c}$ represents the trade-off value of criteria $c$ against cost for scenario $s$, measured in $€ / \mathrm{MWh}$,

$w_{c}$ is weight assigned to the criteria $c$,

$w_{\text {cost }}$ is weight assigned to the criteria cost,

$v_{s, c}$ is the normalization of the score ${ }_{s, c}$, performed automatically in the spreadsheet,

$\max \left\{\right.$ score $\left._{\text {cost }}\right\}$ is the maximum score for the cost criteria $(€ / \mathrm{MWh})$,

$\min \left\{\right.$ score $\left._{\text {cost }}\right\}$ is the minimum score for the cost criteria $(€ / \mathrm{MWh})$.

The parcel in the right of equation (3), which acts as the inverse action taken to transform score $e_{s, c}$ in $v_{s, c}$, ensures that values of $T_{s, c}$ are rescaled to $€ / \mathrm{MWh}$. The value of this trade-off can also be presented as ratio against the minimum cost solution, as described in equation (3)

$T_{s, c}(\%)=\frac{T_{S, c}}{\min \left\{\text { score }_{\text {cost }}\right\}} \times 100$

In Table 3 we present an example of the calculation of the tradeoff performed for the criterion $C_{3}$, "energy dependency".

In the MCDA tool, the user is always presented with the $T_{S, c}(\%)$, the percentage of the costs that this increment represents in relation to the coal scenario cost (minimum cost solution). In the given example where "cost" is assumed to have the double of the weight of "dependency" and for the Maximum Renewable Scenario (last column of the table) the obtained trade-off value is $1.31 € / \mathrm{MWh}$ or $5.5 \%$ (1.31/23.75). This means that the user would accept that having a solution with $28 \%$ of energy dependency would be worth a $5.5 \%$ increment of cost, above the "coal" scenario cost. If he finds the tradeoff too high or too low, the user may now proceed to try different weights according to his perception, for every criteria, given that calculation is simple and instantaneous in the Excel spreadsheet.

\subsection{Implementation}

The MCDA tool ${ }^{2}$ we created for this work is implemented in an Excel worksheet with 5 Sheets, as follows:

[1. General Instructions] The purpose of the tool is presented, as well as a summary of each of the following pages.

[2. Scenarios] The scenarios are presented in the form of graphics of installed power and produced electricity. Energy dependency ratio, $\mathrm{CO}_{2}$ emissions and costs information are also displayed graphically.

[3. Instructions] Instructions for the following sheet are presented, along with an example.

[4. Impact Evaluation and Weighting] Here the user is presented with the 13 criteria, along with explanations of every one of them. The user then fills the required cells, according to what he percepts to be the impacts generated by each scenario. Tradeoffs are presented.

[5. Results] Results are printed: both ranking of scenarios and contribution of each criterion are given.

Some examples of the tool in use are presented in Figs. 3 and 4. Fig. 3 presents an example of the user's views of the MCDA tool for the $C_{2}$ criterion (National Industry). The scale for this criterion ranges from 1 (Low dynamics in industry) to 5 (Leadership of industry, resulting in capacity for exporting), and the user has assigned the impacts for $I_{s, c}$ : $I_{\text {base, national industry }}=4, I_{\text {natural gas, national }}$ industry $=2$, and so on. The blue cell is the weight of the criterion, assigned as 20 in the example.

Following the explanation of the trade-off calculation given in the previous section, the information displayed in the plot indicates that the user finds acceptable to increase the costs in $2.20 \%$, in order to increase the national industry dynamics from score 2 to score 5 . In other words, the user considers to increase the dynamics of national industry from "coal" or "national gas" levels, to the "maximum renewable" levels, and believes that this increase on the dynamic of national industry is worth a costs increase costs of $2.2 \%$. It is also implicit that the user believes costs could be increased in $1.47 \%$ if national industry would reach a score equal to 4 instead of 2 .

Finally, the Results sheet contains two plots, as can be seen on Fig. 4: the one on the top, showing the overall ranking for the scenarios, and the one on the bottom showing the weight of each criterion. The ranking is scaled so that the best scenario is scored by 100. On the given example, "coal" scenario is the most rated, while the "Cost" criterion is assigned as the most important.

\section{Results and discussion}

The collaboration with academics took place in two phases. In the first place, the issues that should be included in power planning decision-making were collected with semi-structured interviews constructed over questions raised in the literature. The results of this exploratory research are described in Ref. [5]. In a second phase, the MCDA tool was sent by e-mail to approximately 60 academics, with background in energy, either from Economics or Engineering (Power Systems/Energy/Environment/Mechanical). The eleven experts that proceeded to the evaluation of the scenarios did it in a period of six weeks. Six of them responded to the tool by themselves, while the other five respondents were aided in a personal interview, which they found helpful and less timeconsuming.

\footnotetext{
${ }^{2}$ The tool is available for download in http://sepp.dps.uminho.pt/.
} 


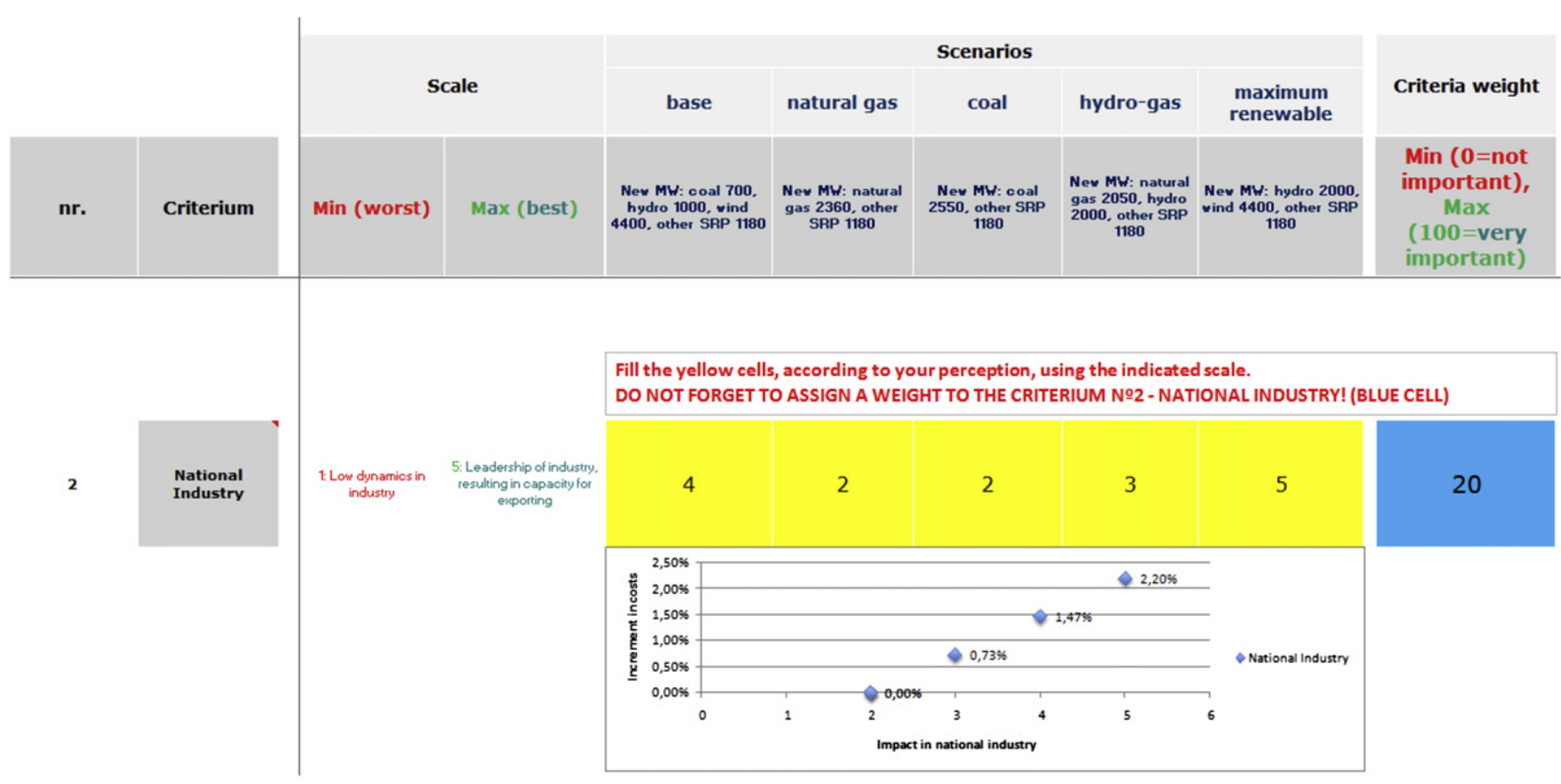

Fig. 3. MCDA tool environment (Excel Sheet 4): Impacts and criteria weighting.

Fig. 5 aggregates the results for criteria weight, which were normalized for each respondent, so that the highest weight equals 1 and the lowest equals 0 .

Costs prevailed as the most important criterion, followed by energy dependency and closely followed by two social concerns: public health and employment. Least important criteria were noise, visual impact, land use, investment in the transmission grid and local income.

The resulting rankings are presented in Table 4. There are no dominated solutions, which means that no scenario performs always worse than any other scenario.

Even in the case that cost is regarded as the most important criterion, the best solution can either be the cheapest or the most expensive, depending on the weights assigned to other criteria: the proof is that "Coal" and "Maximum Renewable", the cheapest and the most expensive scenarios respectively, were the ones that ranked first more often (4 times each).

The only scenario that never ranked first, for any respondent, was "Hydro-Gas". However, it is a balanced scenario, since it only ranks in the last place twice, while "Maximum Renewable" and "Natural Gas" rank in the last position for three respondents' profiles. On the other hand, "Base" is the only scenario that never ranked last place, although only ranks first for two respondents.

The obtained results confirm that costs are still the main obstacle for the incorporation of more renewable energy in electricity systems; this is not an unexpected outcome and as in Ref. [16] case, the obtained scenario ranking was also very sensitive to the input of costs weight.

These results showed, in first place, that respondents felt it was important to trade-off costs with other criteria, demonstrating hence the utility of multi-criteria methodologies. Only on rare occasions did a respondent assign zero to the weight of one criterion, but was free to do it in any criterion he wished to (if he assigned zero to all criteria besides costs, obviously the Coal scenario would be the first in the ranking, since it is the least cost solution).

Secondly, the results indicate that the magnitude of the tradeoff induces the divergence in the final rankings. For example, for the second most rated criterion, energy dependency, one respondent suggested that more information should be given when valuating this criterion ("in the worst case for fuel cost projections, how much would the price of the solution increase?"), otherwise it becomes difficult to state how much would he be willing to valuate the criterion. However, using more information would significantly increase the response time.

Fig. 6 presents the contrast between respondents favourable to "Coal" and "Maximum Renewable" scenarios, showing that while the former group clearly place costs above any other criteria, the latter have five similarly valuated criteria: costs, public health, energy dependency, national industry and employment.

\subsection{Comparison of the results with other studies}

Previous works have already addressed the use of MCDA for scenario evaluation under electricity planning objectives, as pointed out in Section 1.2. In general the results obtained for Portugal put in evidence two main aspects: firstly cost remains a fundamental decision variable even for those who favour more renewable scenarios, and secondly, electricity planning evaluation is far from being a consensual matter even when a small number of wellinformed experts are included. As Hobbs and Meier [10] pointed out, trading off attributes often involves conflicting, strongly held values, leading to unstable weights. Based on their experience, the authors state that many energy planners and decision makers are uncomfortable with trade-off questions. Also, the broad diversity of interests and values of the decision makers makes consensus very difficult to achieve in the energy planning process [3].

Talinli's work [17] addressed the specific case of Turkey, and the MCDA was used to evaluate three different scenarios for electricity production. Among the experts invited to participate there were academics, namely two electrical engineers, one mechanical engineer and two environmental engineers, one of which had background in environmental economics. The main difference from their weighting approach to ours is the fact that the experts discussed and agreed to achieve an a priori conclusion of weighting 
RANKING

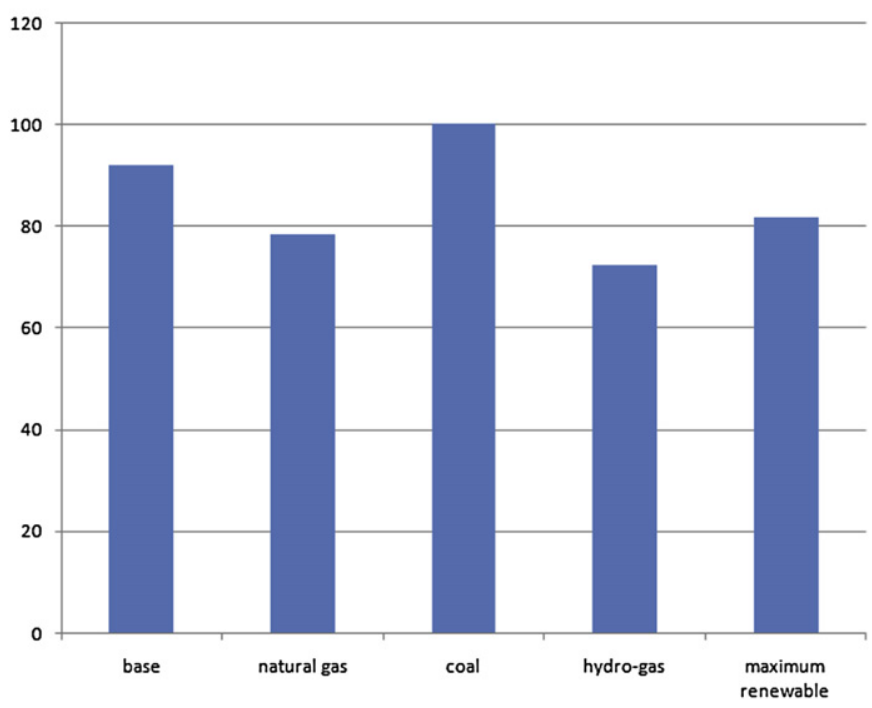

WEIGHTS

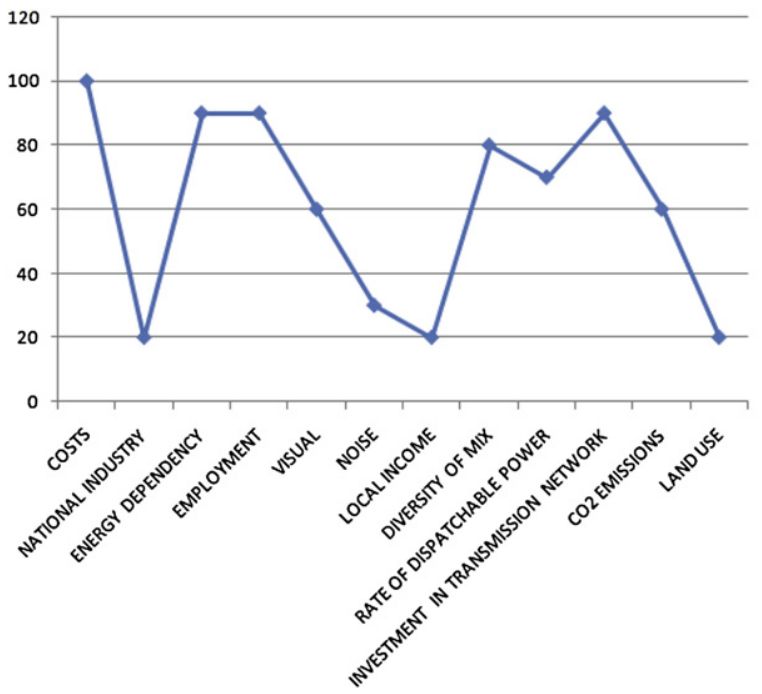

Fig. 4. MCDA tool environment (Excel Sheet 5): results. Here the user can validate his perceptions.

the criteria, whereas we invited the experts to map the differences of opinions. Therefore their study does not allow a sensibility analysis of the tool's performance. The results favoured more "Social Factors" and "Environmental Factors" groups of criteria in detriment of "Technical Properties" and "Economic Factors". All the three highest weight criteria "environmental impact", "environmental risk" and "public acceptance" benefited renewable energy (wind power) scenario, which was the favourite in the final ranking, and this is in line with our conclusions.

Another study addressed North England energy scenarios in 2050 , resourcing to experts' evaluation and to cluster analysis to analyze their eight responses [20]. The authors divide the responses in two groups, first group being "energy as business", which give more value to costs, infrastructure change, security, reliability and deliverability, and the other group being "environment and society first", focussing on lifestyle impacts and security of supply. According to the obtained results "security of supply" (related to natural gas depletion, conflict in the Middle East and volatility of prices) was important for both groups, which in our case is also true to some degree as "energy dependency" and "diversity of mix" were regarded as important to respondents who prefer either "coal" or "maximum renewables".

In another example, this time for Austria, the authors [19] constructed scenarios using different strategies for renewable energy as a whole, so their study focuses on both heating and electricity generation. Sixteen experts and stakeholders were invited to evaluate five different renewable energy scenarios. They used seventeen criteria, some of which are also present in our work $\left(\mathrm{CO}_{2}\right.$ emissions, noise, air and water quality, effect on public budget, security of supply). Although they don't discuss the weights in detail, they derived some conclusions opposed to ours, because their scenario evaluation was very robust, which means that the opinion of 16 different respondents and rankings did not change much. On the other hand, in Ref. [34], the authors weighted seven criteria to rank four scenarios for a Greek island, using PROMETHEE and the obtained preferences varied greatly among the six decision makers.

More recently [35], applied the MCDA methodology PROMETHEE in a German community, where seven scenarios for energy generation (heat and electricity) were evaluated. In their participatory weighting approach they used a "silent negotiation" method and achieved one criteria ranking for the whole group. Security of supply was on the top of the group ranking immediately followed by economic concerns such as the operation of the system and the heat price. The protection of resources appears in the bottom of the list and the employment ranks in second last, what is overtly contrary to our "Maximum Renewable" group, but similar to the "Coal" group.

This comparison to other studies is far from being exhaustive, but allowed to demonstrate how multi-criteria tools can be effective not only for the evaluation of energy technologies as frequently reported but also on the evaluation/ranking of scenarios. This requires a much more complex exercise as it implies resourcing to long-term forecasts on an unstable sector along with the previous definition of scenarios and criteria. Furthermore, the problem is much more regional or national dependent, as demonstrated in the studies addressing specific countries or regions as case studies. Nevertheless, it is becoming evident a trend to increasingly weight security of supply and environmental concerns. Cost remains a fundamental decision variable but the importance of social aspects such as job creation is obviously strongly driven by the socioeconomic conditions of the region under analysis.

\subsection{Sensitivity analysis}

Given that costs were the highest valued criterion, their weight is the most decisive contribution to the final ranking and the relative importance of other criteria is, therefore, overshadowed. Departing from the results obtained with the experts, three average experts' profiles can be created, based on the aggregation of results. The "average profile" reflects the average input from the eleven respondents, while the "coal profile" is the result of the average input from the respondents who ranked the "Coal" scenario in the first place whereas the "renewable profile" had the preference for the "Maximum Renewable" scenario. These results, presented in Table 5, were normalized so that the sum of criteria's weight is 100 ; note that the costs were left aside because the sensitivity analysis will be performed in relation to this criterion.

The objective of the sensitivity analysis is to realize how the ranking of preferred scenarios evolves within each profile, from a situation where costs are not important, to other situation where costs weight much more than the other criteria. This is achieved by calculating the break-even costs weight $\left(B E C W_{p}\right)$, for each profile $p$, defined as the weight assigned to costs for which the preferred scenario becomes "Coal" (the least cost scenario).

As stated in a previous section, the highest the Additive Value Function (AVF) values are, the better the scenario ranks. When the 


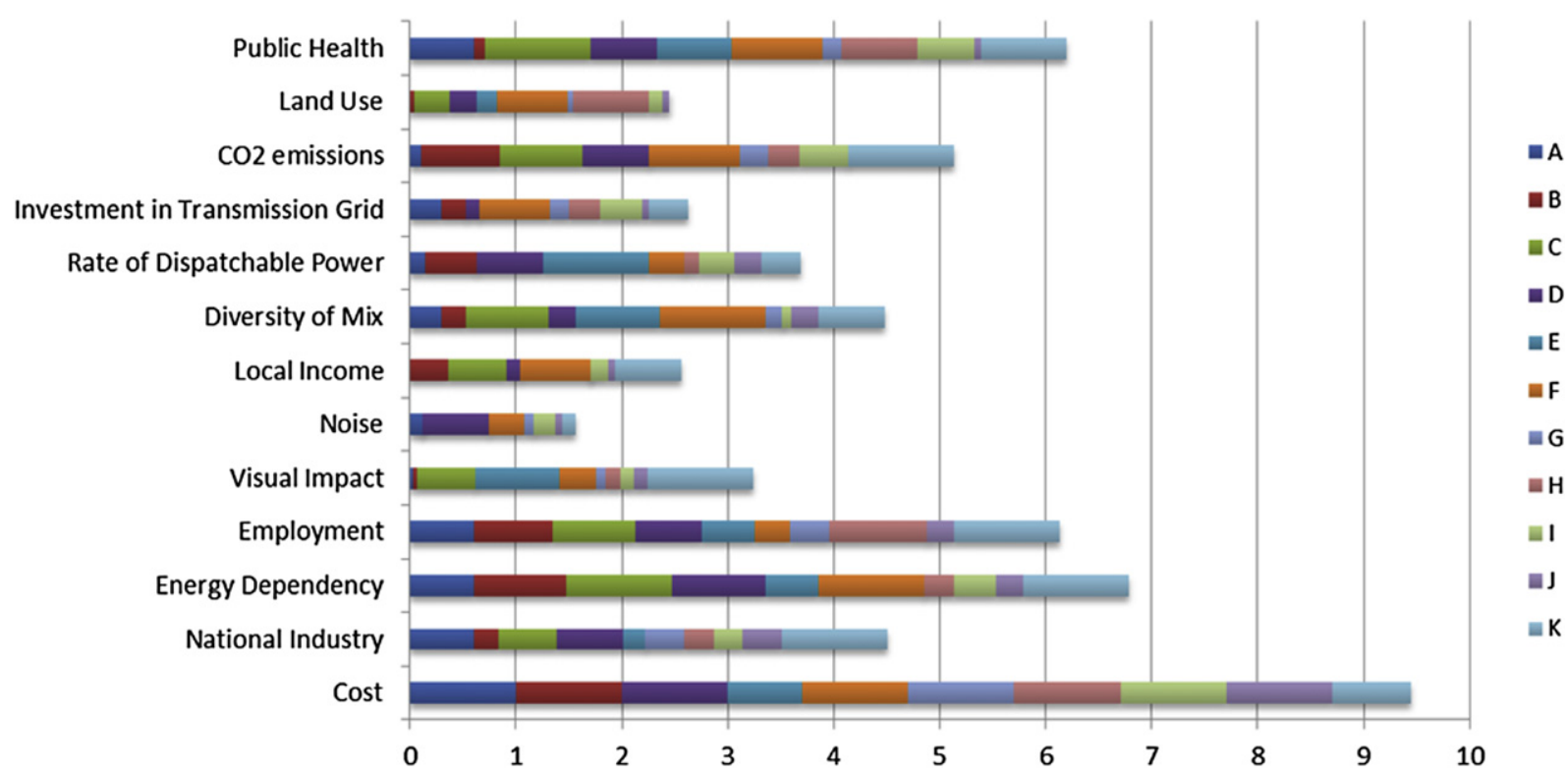

Fig. 5. Aggregation of results. Criteria weights were normalized for each respondent, so that the most important criterion weights 1 and the least important weights 0 .

Table 4

Scenario ranking according to respondents' perception.

\begin{tabular}{llllllllllll}
\hline \multirow{2}{*}{ Scenario } & \multicolumn{1}{l}{ Respondents } & & & & & & & \\
\cline { 2 - 11 } & A & B & C & D & E & F & G & H & I & J & K \\
\hline Base & 2 & $\mathbf{1}$ & 3 & 2 & 4 & 2 & 3 & $\mathbf{1}$ & 4 & 2 & 2 \\
Natural gas & 5 & 5 & 4 & 5 & 3 & 4 & 2 & 4 & $\mathbf{1}$ & 4 & 5 \\
Coal & 3 & 3 & 5 & 4 & $\mathbf{1}$ & $\mathbf{1}$ & $\mathbf{1}$ & 3 & 2 & $\mathbf{1}$ & 4 \\
Hydro-gas & 4 & 4 & 2 & 3 & 2 & 5 & 4 & 5 & 3 & 3 & 3 \\
Maximum renewable & $\mathbf{1}$ & 2 & $\mathbf{1}$ & $\mathbf{1}$ & 5 & 3 & 5 & 2 & 5 & 5 & $\mathbf{1}$ \\
\hline
\end{tabular}

The bold values represents the scenario that ranked first for each respondent.

weight of costs is high enough, the costs are determining the preference, so the Coal scenario, the least costly, will appear as the preferred scenario. On the other hand, when no importance is given to costs, it is unanimous for the three profiles that the preference ranking is, from highest to lowest, "maximum renewable", followed by "base", "hydro-gas", "natural gas" and "coal" (Fig. 7).

The BECW is, for Average, Coal and Renewable profiles, 34.4, 10.7 and 50 respectively. Note that for a cost weight equivalent to 10.7 in the "Renewable" profile, the "coal" scenario is still the last in the ranking, while for the "coal profile", Coal scenario would be the

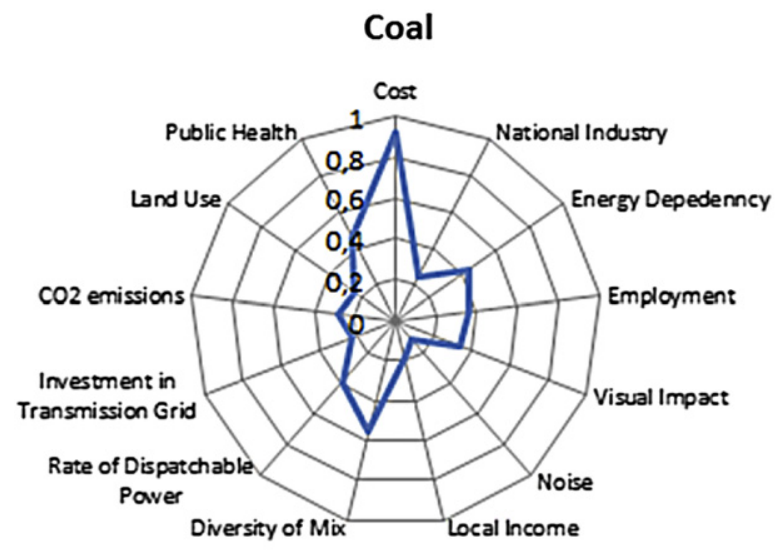

Table 5

Aggregation of the results of respondents according to their preferred scenarios.

\begin{tabular}{lcrc}
\hline Experts profile & Average & Coal & Renewable \\
\hline National industry & 7.9 & 6.2 & 12.1 \\
Energy dependency & 14.0 & 11.4 & 15.1 \\
Employment & 12.3 & 9.5 & 13.0 \\
Visual impact & 5.3 & 8.8 & 6.8 \\
Noise & 3.5 & 3.2 & 3.8 \\
Local income & 4.7 & 4.8 & 5.7 \\
Diversity of mix & 9.1 & 14.4 & 8.5 \\
Rate of dispatchable power & 7.7 & 10.3 & 5.0 \\
Investment in transmission grid & 5.5 & 5.9 & 3.5 \\
CO emissions & 10.4 & 7.4 & 10.9 \\
Land use & 6.0 & 6.4 & 2.5 \\
Public health & 13.4 & 11.8 & 13.2 \\
& & & \\
Total & $\mathbf{1 0 0}$ & $\mathbf{1 0 0}$ & $\mathbf{1 0 0}$ \\
\hline
\end{tabular}

preferred one. This shows that the relative importance of other criteria is indeed different among the different profiles, and that for those whose preferred scenario was "maximum renewable" a higher weight cost would be needed to balance the importance given in the other criteria.

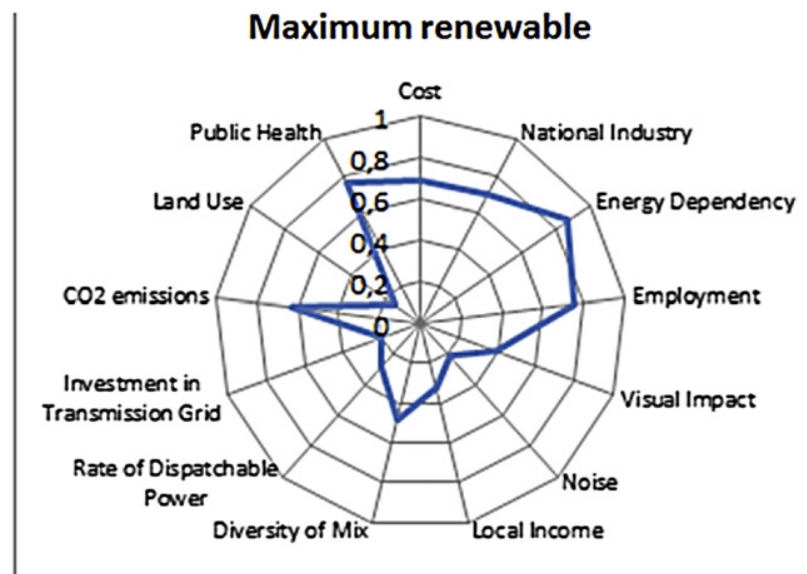

Fig. 6. Relative weighting among respondents who preferred the "coal" and "maximum renewable scenarios". Weights were normalized and then averaged. 

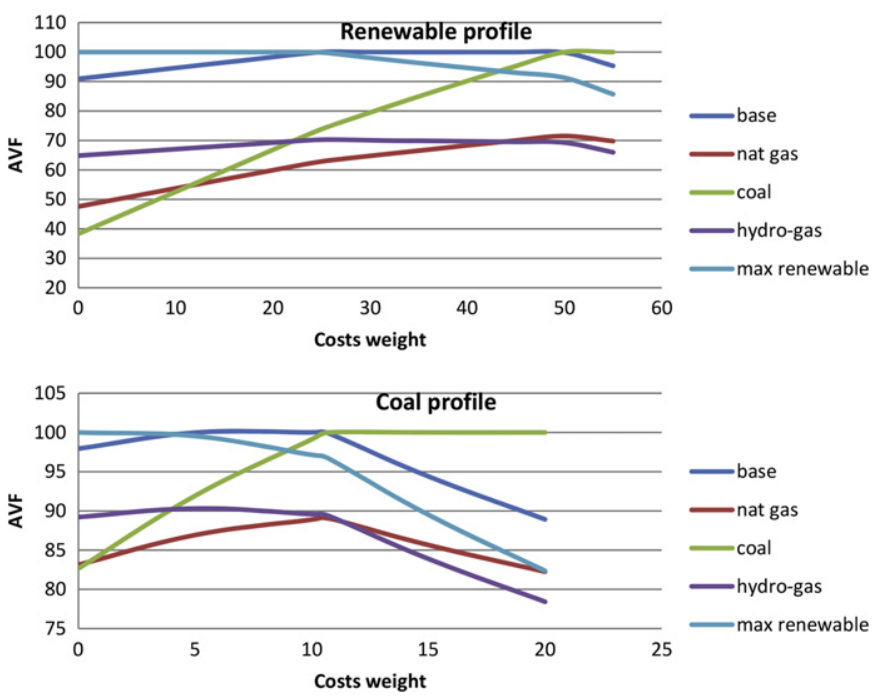

Fig. 7. Calculation of the break-even costs weight (results are normalized so that the best AVF $=100$ )

The sensitivity analysis demonstrates that although cost remains as a fundamental criterion, other impacts should not be neglected in long-term energy decision-making. According to these experts input, at least the external energy dependency along with criteria directly related with social welfare must be equally recognized as relevant.

\section{Conclusion}

In this paper we addressed the problem of long-term strategic electricity decision-making. Recognizing the diversity of criteria to be taken into account, we propose a tool to evaluate scenarios for electricity production. The tool was built in a userfriendly environment and uses multi-criteria decision analysis comprising a set of thirteen criteria, ranging from economic concerns, to environmental and social as well as technical issues. The methodology combines an additive value function that aggregates results from direct weighting and trade-off analysis.

The proposed tool was used on the particular case of Portugal, for the evaluation of a set of five hypothetical scenarios drawn for the Portuguese power generation system in 2020. The scenarios consisted in a moderated scenario following a business-as-usual approach, a second scenario mainly relying on investment in new natural gas power plants, a third scenario mainly relying on investment in new coal power plants, a fourth scenario relying on investment in a mix of new hydro and gas power plants and a fifth scenario relying on investment in a mix of new hydro and wind power plants. A group of experts from academia, Engineers and Economists related to the energy sector, participated in the evaluation of these scenarios.

From the results obtained, the general conclusion is that all the respondents would be willing to increase the costs of power generation if other issues than the economical ones were to be taken into account. This fact alone proves the utility of MCDA. The evaluated scenarios were ranked differently by respondents with different perspectives, what is not unexpected when using multicriteria methodologies. In fact, only one of the scenarios, "HydroGas", was not chosen to be the preferred by any of the eleven respondents.

Departing from the obtained results and aggregating two groups of experts, a first one containing all the responses of those whose preferred scenario was "Coal", and a second group containing the responses of the respondents which ranked "Maximum Renewable" on the first place, led us to conclude that different attitudes exist towards different criteria. While the former place costs above all the other criteria in terms of importance, for the latter, costs, public health, energy dependency, national industry and employment are similarly valued. Other highly valued criterion by this group was the employment. When performing MCDA, depending on the weight assigned to these criteria, the cost can lose relative importance and least costly solutions may rank firstly.

This work aimed to propose a simple but reliable and scientifically based MCDA approach to address the problem of electricity scenarios selection. By resourcing to experts we expect to overcome, or at least moderate, the volatility of general opinions concerning specific technologies frequently driven by public groups or opinion makers. Notwithstanding, it should be underlined that the results are still highly permeable to the socio-economic moments of the country or region under analysis, especially in what concerns highly social impacting variables such as cost, employment or external energy dependency. Although the present economic crisis is seeing the investors reluctant to mobilize capitals to the renewable energy technologies [36], our study indicates that cost by itself may hardly be a justification for long-term electricity strategic decisions, demonstrating once more the importance of resourcing to MCDA and experts' judgement to support sustainable decision-making processes. Although the cost concern is in line with the literature [16] recent works such as Refs. [37] and [38] demonstrate already the importance of criteria related to job creation for the sustainable electricity planning, given that high unemployment during economic crisis, rends the societal opportunity costs of labour close to zero. This appears to be perceived by the experts who favoured the "maximum renewable" scenario, since they placed emphasis in job creation. Recent studies addressing the Portuguese energy case [39], during the present economic crisis, indicate that strategic thinking must go beyond costs and focus on energy dependency, if the EU (European Union) package goals are to be accomplished. Our present work shows that "energy dependency" is a transversal concern, in the line with what [20] verified in their MCDA assessment. Among the participants in our study, this criterion was the most valuated criterion, after costs. However, it is more valuated by those who favour the "maximum renewable" scenario than by those who favour "coal" scenario.

Although recognizing the complexity of the electricity systems and as so the need to address the evaluation process supported on experts' opinion, the importance of social acceptance must not be neglected. In fact, being the public acceptance of technologies a fundamental aspect to ensure the success of strategic scenarios, our future work envisages the implementation of a large scale survey aiming to evaluate public knowledge and acceptance for different electricity generation technologies in Portugal, and addressing in particular renewable energy projects.

\section{Acknowledgements}

This work was financed by: the QREN Operational Programme for Competitiveness Factors, the European Union - European Regional Development Fund and National Funds - Portuguese Foundation for Science and Technology, under Project FCOMP-010124-FEDER-011377 and Project Pest-OE/EME/UI0252/2011. Authors wish to thank all the academics that collaborated in the interviews. 


\section{References}

[1] European Comission. 2011 Monitoring report of the EU sustainable development strategy; 2011.

[2] Loken E. Use of multicriteria decision analysis methods for energy planning problems. Renewable and Sustainable Energy Reviews 2007;11:1584-95.

3] Ferreira P, Araújo M, OKelly M. The integration of social concerns into electricity power planning: a combined Delphi and AHP approach. Handbook of power systems. 1st ed. p. 323-64.

[4] Ribeiro F, Ferreira P, Araújo M. The inclusion of social aspects in power planning. Renewable and Sustainable Energy Reviews 2011;15:4361-9.

[5] Ribeiro F, Ferreira P, Araújo M. A methodology to address social concerns in electricity planning. In: Proceedings of the Dubrovnik conference on sustainable development of energy, water and environment systems, Dubrovnik, Croatia, 25-29 September 2011. p. 321.

[6] Wang J-J, Jing Y-Y, Zhang C-F, Zhao J-H. Review on multi-criteria decision analysis aid in sustainable energy decision-making. Renewable and Sustainable Energy Reviews 2009;13:2263-78.

[7] Scott JA, Ho W, Dey PK. A review of multi-criteria decision-making methods for bioenergy systems. Energy 2012;42(1):146-56.

[8] Chinese D, Nardin G, Saro O. Multi-criteria analysis for the selection of space heating systems in an industrial building. Energy 2011;36(1):556-65.

[9] Jovanovic M, Turanjanin V, Bakic V, Pezo M, Vucicevic B. Sustainability estimation of energy system options that use gas and renewable resources for domestic hot water production. Energy 2011;36(4):2169-75.

[10] Hobbs B, Meier P. Energy decisions and the environment: a guide to the use of multicriteria methods. In: International series in operations research \& management science. Kluwer Academic Publishers; 2000.

[11] Kahraman C, Kaya İ. A fuzzy multicriteria methodology for selection among energy alternatives. Expert Systems with Applications 2010;37(9): $6270-81$.

[12] Kaya T, Kahraman C. Multicriteria renewable energy planning using an integrated fuzzy VIKOR \& AHP methodology: the case of Istanbul. Energy 2010; 35(6):2517-27.

[13] Choudhary D, Shankar R. An STEEP-fuzzy AHP-TOPSIS framework for evaluation and selection of thermal power plant location: a case study from India. Energy 2012;42(1):510-21.

[14] Prete C, Hobbs BF, Norman CS, Cano-Andrade S, Fuentes A, von Spakovsky MR, et al. Sustainability and reliability assessment of microgrids in a regional electricity market. Energy 2012;41(1):192-202.

[15] McCollum D, Krey V, Riahi K. An integrated approach to energy sustainability. Nature Climate Change 2011;1:428-9.

[16] Heinrich G, Basson L, Cohen B, Howells M, Petrie J. Ranking and selection of power expansion alternatives for multiple objectives under uncertainty. Energy 2007;32(12):2350-69.

[17] Talinli I, Topuz E, Akbay M. Comparative analysis for energy production processes (EPPs): sustainable energy futures for Turkey. Energy Policy August 2010;38(8):4479-88.

[18] Trutnevyte E, Stauffacher M, Scholz RW. Linking stakeholder visions with resource allocation scenarios and multi-criteria assessment. European Journal of Operational Research 16 June 2012;219(3):762-72.

[19] Madlener R, Kowalski K, Stagl S. New ways for the integrated appraisal of national energy scenarios: the case of renewable energy use in Austria. Energy Policy December 2007;35(12):6060-74.
[20] Shackley S, McLachlan C. Trade-offs in assessing different energy futures: a regional multi-criteria assessment of the role of carbon dioxide capture and storage. Environmental Science \& Policy June 2006;9(4):376-91.

[21] Jovanović M, Afgan N, Radovanović P, Stevanovi\&cacute V. Sustainable development of the Belgrade energy system. Energy May 2009;34(5):532-9.

[22] REN. Informação mensal, sistema electroprodutor [in Portuguese]. Available in: Redes Energéticas Nacionais, http://www.centrodeinformacao.ren.pt/; 2011.

[23] INAG. Plano nacional de barragens com elevado potencial hidroeléctrico Instituto da Água; 2007 [in Portuguese].

[24] REN. A energia eólica em Portugal. Redes Energéticas Nacionais [in Portuguese]. Available in: http://www.centrodeinformacao.ren.pt/; 2011.

[25] Pereira S, Ferreira P, Vaz AI. Strategic electricity planning decisions. In: Proceedings of the Dubrovnik conference on sustainable development of energy, water environment systems, Dubrovnik, Croatia, 25-29 September 2011. p. 590

[26] República Portuguesa. Plano nacional de acção para as energias renováveis ao abrigo da directiva 2009/28/CE; 2009 [in Portuguese].

[27] Organization for Economic Co-operation and development/International Energy Agency, editor. Projected costs of generating energy. Paris, France: Organization for Economic Cooperation and Development; 2010.

[28] Bishop JD, Amaratunga GA, Rodriguez C. Using strong sustainability to optimize electricity generation fuel mixes. Energy Policy 2008;36:971-80.

[29] Joskow P. Apples and oranges: don't compare levelized cost of renewables. The Electricity Journal 2010;23:3-5.

[30] Mills A, Wiser R, Porter K. The cost of transmission for wind energy in the United States: a review of transmission planning studies. Renewable and Sustainable Energy Reviews 2012;16:1-19.

[31] Chatzimouratidis AI, Pilavachi PA. Multicriteria evaluation of power plants impact on the living standard using the analytic hierarchy process. Energy Policy 2008;36:1074-89.

[32] European Commission. External costs: research results on socioenvironmental damages due to electricity and transport. European Commission; 2003.

[33] Krey B. Scope of electricity efficiency improvement in Switzerland until 2035; 2008.

[34] Tsoutsos T, Drandaki M, Frantzeskaki N, Iosifidis E, Kiosses I. Sustainable energy planning by using multi-criteria analysis application in the island of Crete. Energy Policy May 2009;37(5):1587-600.

[35] Wilkens I, Schmuck P. Transdisciplinary evaluation of energy scenarios for a German village using multi-criteria decision analysis. Sustainability 2012;4 604-29.

[36] Masini A, Menichetti E. The impact of behavioural factors in the renewable energy investment decision making process: conceptual framework and empirical findings. Energy Policy January 2012;40:28-38.

[37] Oikonomou V, Flamos A, Gargiulo M, Giannakidis G, Kanudia A, Spijker E, et al. Linking least-cost energy system costs models with MCA: an assessment of the EU renewable energy targets and supporting policies. Energy Policy May 2011;39(5):2786-99.

[38] Lund H, Hvelplund F. The economic crisis and sustainable development: the design of job creation strategies by use of concrete institutional economics. Energy July 2012;43(1):192-200.

[39] Oliveira Henriques C. Henggeler Antunes C. Interactions of economic growth, energy consumption and the environment in the context of the crisis a study with uncertain data. Energy. Available online 10 May 2012. 